\title{
Optimization of Weld Bead Width in Tungsten Inert Gas Welding of Austenitic Stainless Steel Alloy
}

\author{
Vinod Kumar* \\ Mechanical Engineering Department, Thapar University, Patiala, India \\ *Corresponding author: vsingla5@yahoo.com
}

Received April 02, 2014; Revised April 29, 2014; Accepted May 03, 2014

\begin{abstract}
This paper investigates the effects of process parameters on weld bead width of austenitic stainless steel SS-310 in tungsten inert gas welding. The four parameters namely welding current, type of gas, gas flow rate and included angle of weld plates during butt joint were varied at three levels. The DOE approach was used to design experimental conditions. Orthogonal array L9 was used for carrying out experimentation. The optimization of weld bead width in tungsten inert gas welding of austenitic stainless steel alloy was done using ANOVA. The minimum value of bead width of SS 310 is $8.27 \mathrm{~mm}$ at current value 130A.
\end{abstract}

Keywords: weld bead width, TIG, ANOVA, DOE

Cite This Article: Vinod Kumar, "Optimization of Weld Bead Width in Tungsten Inert Gas Welding of Austenitic Stainless Steel Alloy.” American Journal of Mechanical Engineering, vol. 2, no. 2 (2014): 50-53. doi: 10.12691/ajme-2-2-4.

\section{Introduction}

Tungsten inert gas (TIG) welding is an arc welding process that uses a non-consumable tungsten electrode to produce the weld. The weld area is protected from atmospheric contamination by an inert shielding gas and a filler metal is normally used though some welds known as autogenous welds, do not require it [1]. A constant-current welding power source produces energy which is conducted across the arc. The necessary heat for Gas Tungsten Arc Welding (TIG) is produced by an electric arc maintained between a non-consumable tungsten electrode and the part to be welded. The shielding gases act as a blanket during welding and exclude the active properties in the surrounding air. The heat-affected zone, the molten metal, and the tungsten electrode are all shielded from the atmosphere. Likewise all welding processes, TIG welding can be considered as multi-input and multi-output process [2]. These input parameters must be carefully controlled in order to obtain a good welded joint. The weld bead shape is a very important factor determining the quality of welds. The knowledge of how welding process parameters affect weld bead geometry is important because it can be applied in automatic and semiautomatic control of arc welding processes where optimal selection of input parameters is required for high productivity and cost effectiveness. Theoretically, an extremely thin fused layer might be sufficient for connecting the parts to be joined. The fusion layer should also not be thicker than necessary in order to avoid wasting of energy, edge burn-off, sagging of the weld pool and deep weld end craters of welds. Weld bead width is directly proportional to arc current, welding voltage and electrode diameter and indirectly proportional to the welding speed. The mechanical properties of welds are affected by the weld-bead shape hence its close control is must. The weld bead shape is a very important factor determining the quality. A welding joint is considered to be a good or of high quality if weld bead width and weld bead height are minimum in size. If bead width and bead height is less, the distortion of welded plates and residual stresses are least. Traditional methods of determining input parameters that result in minimum weld bead geometry are time consuming and depend on expertise level of the welder. This involved carrying out a large number of experiments. The number of experiment goes on increasing with increase in input parameters. Taguchi design of experiments involving orthogonal array is a very special tool to carry out such study. In recent years, the Taguchi method has become a powerful tool for improving productivity during research and development so that high quality can be obtained quickly and at low cost [3]. A statistical technique ANOVA was applied in order to determine significant and non-significant parameters. ANOVA can infer some important conclusions based on analysis of the experimental data and moreover it reveals the level of significance of influence of factor(s) on particular response.It is the statistical treatment applied to the results of the experiments in determining the percent contribution of each parameter against a stated level of confidence. The study of ANOVA table for a given analysis helps to determine which of the parameters need control and which do not [4]. The use of signal-to-noise $(\mathrm{S} / \mathrm{N})$ ratio in analysis provides a quantitative value for comparison of variation in response. The desirable response characteristic for bead width and bead height is lower-thebetter. In this design situation, response is the type of 
“'lower is better', which is a logarithmic function based on the mean square deviation (MSD), given by

$$
S / N_{L B}=-10 \log (M S D)=-10 \log \left(\frac{1}{r} \sum_{i=1}^{\prime} y_{i}^{2}\right)
$$

where $(\mathrm{S} / \mathrm{N})$ is the inspection index, defined as the signalto-noise ratio (unit:dB), $r$ is the number of repetitions for each trial, independent of the values assigned to noise factors, and $y_{i}$ is the value of the response obtained in the $\mathrm{i}^{\text {th }}$ repetition of the trial.

The austenitic stainless steel contains 16-26 \% Chromium and 6-12 \% Nickel. These steels were developed for use in both mild and severe corrosive conditions. It can maintain face-centered cubic (FCC) structure over a wide range of temperatures. Austenitic stainless steels have been used widely by the fabrication industry owing to their excellent high temperature and corrosion resistance properties. SS 310 is an austenitic stainless steel with a higher amount of Chromium and Nickel content. The restricted Carbon helps in better welding and formability of this steel. It finds applications where steel is to be exposed to higher temperature and severe service conditions. SS310 can maintain high creep strength and good mechanical properties at higher temperatures.

\section{Scheme of Investigation}

In order to achieve the desired objectives, following steps were followed

- Selection of Base metal and filler metal.

- Identify important weld parameters.

- Pilot study to finalise values of parameters.

- Working range of process parameters.

- Selection of orthogonal array.

- Conducting the experiment as per selected orthogonal array.

- Measurement of bead width and bead height.

Stainless steel plates of grade SS-310 were used in the form of plates of sizes 160 X $100 \times 6 \mathrm{~mm}$. The filler material of same grade in form of wires of size 2.5 X 1000 mm was in making of butt welded joints. A pilot study was carried out before finalising the range of process parameters (current, type of gas, gas flow rate and grove angle). The selection was made depending on bead inspection and penetration of heat energy on the bottom side of plate. On basis of this the values of current chosen for present study were $130 \mathrm{~A}, 170 \mathrm{~A}, 210 \mathrm{~A}$. The numbers of process parameters considered in this study were four and each level was varied at three levels. Hence, L9 orthogonal array was finalised. Non-consumable Thoriated Tungsten electrode having $3 \mathrm{~mm}$ diameter was used to establish arc with work pieces and hence to weld. Finalised range of process parameters are shown in Table 1. and degrees of freedom allotted are shown in Table 2.

Table 1. Process parameters and range

\begin{tabular}{|c|c|c|c|c|}
\hline \multirow{2}{*}{ Welding Parameters } & \multirow{2}{*}{ Symbol } & \multicolumn{3}{|c|}{ Levels } \\
\cline { 3 - 5 } & & 1 & 2 & 3 \\
\hline Current & $\mathrm{I}$ & $130 \mathrm{~A}$ & $170 \mathrm{~A}$ & $210 \mathrm{~A}$ \\
\hline Angle & $\Theta$ & $60^{\circ}$ & $75^{\circ}$ & $90^{\circ}$ \\
\hline Gas Type & $\mathrm{G}$ & $\mathrm{Ar}$ & $\mathrm{He}$ & $\mathrm{Ar}+\mathrm{He}(50: 50)$ \\
\hline Gas flow rate (L/min) & $\mathrm{F}$ & 9. & 12 & 15 \\
\hline
\end{tabular}

Table 2. Degrees of freedom

\begin{tabular}{|c|c|c|}
\hline S. No. & Parameters & DOF \\
\hline 1 & Welding Current & 2 \\
\hline 2 & Shielding gas type & 2 \\
\hline 3 & Groove angle & 2 \\
\hline 4 & Gas flow rate & 2 \\
\hline & Total & $\mathbf{8}$ \\
\hline
\end{tabular}

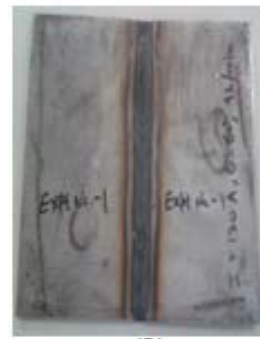

(1)

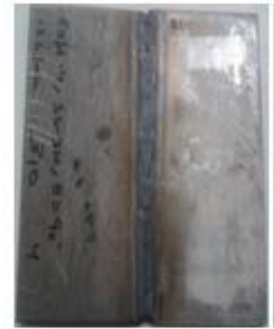

(4)

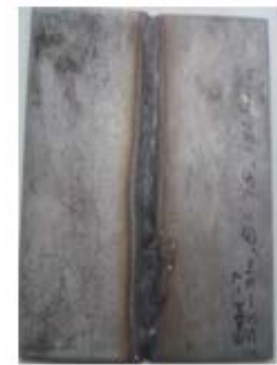

(7)

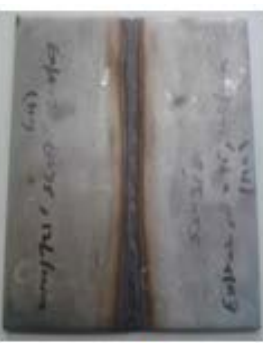

(2)

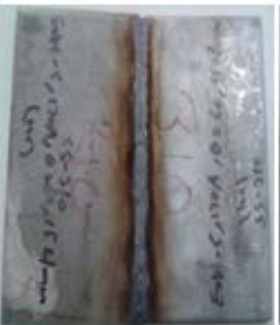

(5)

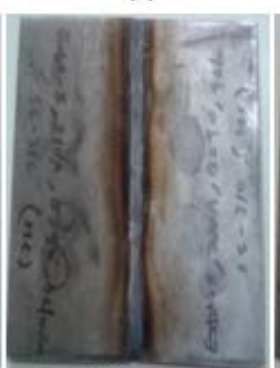

(8)

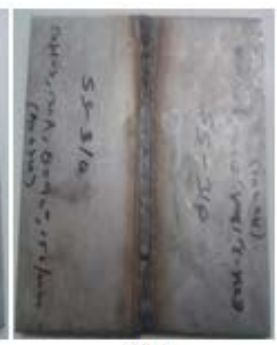

(3)

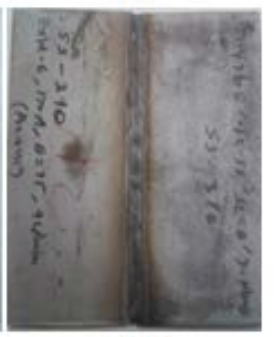

(6)

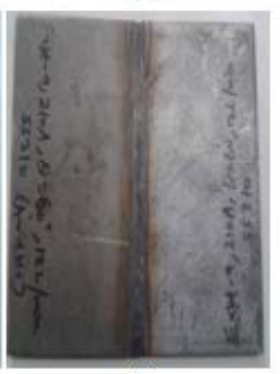

(9)
Figure 1. Welding specimens of SS 310 (1-9)

Weld bead width was measured and the result shown are in Table 3. The graphical representation of bead width is shown in Figure 2 and Figure 3 ahead showing the variations in all welded samples for stainless steel grade SS 310.

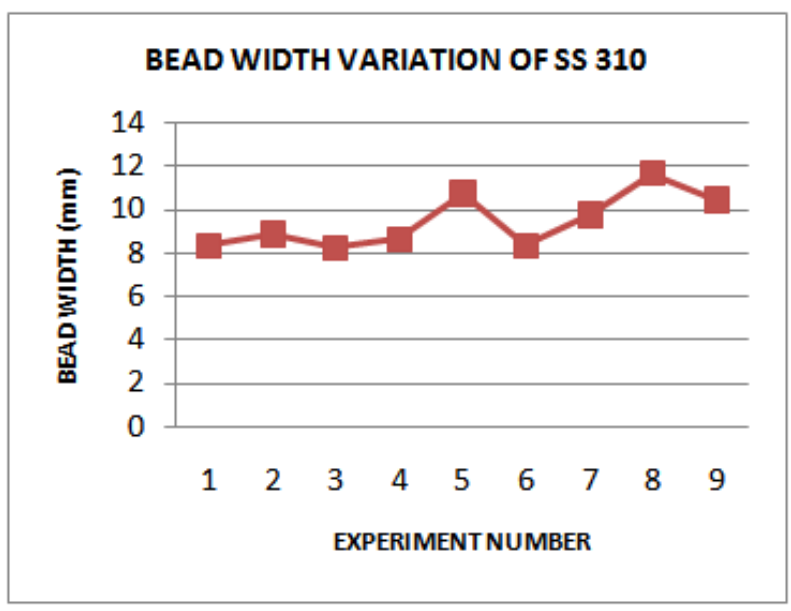

(a)

Figure 2. Graph on (a) bead width 

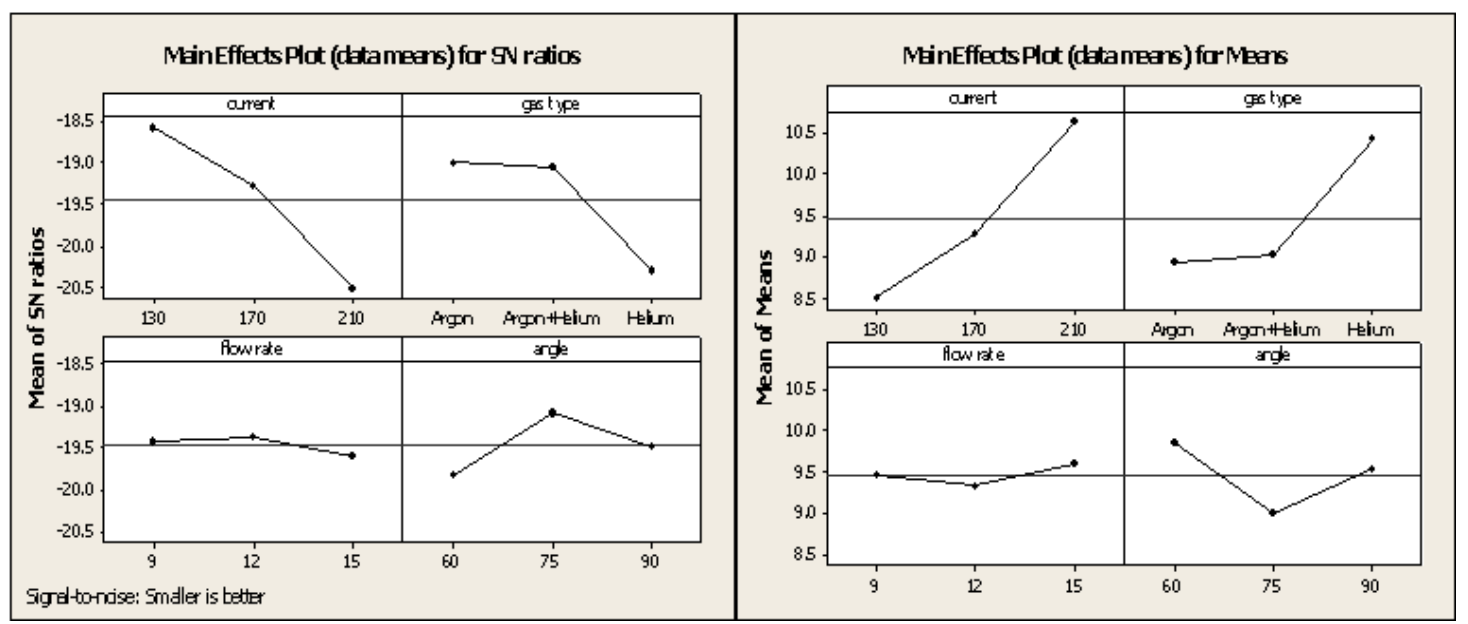

Figure 3. Main effect plot for SN ratios and means of Weld Bead width of SS 310

Table 3. Bead width and height of SS 310

\begin{tabular}{|c|c|c|c|c|c|c|c|c|c|}
\hline Expt. No. & $\mathbf{1}$ & $\mathbf{2}$ & $\mathbf{3}$ & $\mathbf{4}$ & $\mathbf{5}$ & $\mathbf{6}$ & $\mathbf{7}$ & $\mathbf{8}$ & $\mathbf{9}$ \\
\hline Bead Width (mm) & 8.362 & 8.876 & 8.272 & 8.672 & 10.742 & 8.38 & 9.784 & 11.654 & 10.444 \\
\hline
\end{tabular}

It is clear from results so obtained from Table 4 to Table 7

\section{Result Analysis}

\subsection{Result of Bead Width of SS 310}

The results for weld bead width were analysed by using ANOVA in order to identify the significant factors affecting the performance measures. The minimum value of bead width of SS 310 is $8.27 \mathrm{~mm}$ at current value 130A. that current is the most important parameter having the most significant affect on the bead width and then shielding gas type has sub-significant affect, whereas flow rate and groove angle have almost negligible effect on the same. Plot for main effects in Figure 3 shows that with increase in current the value of bead width increases which is not desirable. Among all gases, argon helps to keep bead width minimum.

Table 4. Analysis of variance for SN ratio of weld bead width of SS 310

\begin{tabular}{|c|c|c|c|c|c|c|}
\hline Source & DOF & SS & Variance & F ratio & F (critical) & PC \\
\hline Current & 2 & 5.659 & 2.829 & 65.668 & 19 & 56.940 \\
\hline Gas type & 2 & 3.228 & 1.614 & 37.462 & 19 & 32.105 \\
\hline Flow rate & 2 & 0.086 & 0.043 & 1 & 19 & 3.523 \\
\hline Grove angle & 2 & 0.813 & 0.406 & 9.440 & 19 & 7.432 \\
\hline Total & 8 & 9.787 & & & & 100 \\
\hline Error pooled & 2 & 0.086 & 0.043 & & & 3.523 \\
\hline
\end{tabular}

Table 5. Response table for SN ratio of weld bead width of SS 310

\begin{tabular}{|c|c|c|c|c|}
\hline Level & Current & Gas type & Flow rate & Grove angle \\
\hline 1 & -18.59 & 19.01 & -19.41 & -19.82 \\
\hline 2 & -19.28 & -19.07 & -19.37 & -19.08 \\
\hline 3 & -20.51 & -20.31 & -19.59 & -19.48 \\
\hline Delta & 1.92 & 1.30 & 0.23 & 0.74 \\
\hline Rank & 1 & 2 & 4 & 3 \\
\hline
\end{tabular}

Table 6. Analysis of variance for Means of weld bead width of SS 310

\begin{tabular}{|c|c|c|c|c|c|c|}
\hline Source & DOF & SS & Variance & F ratio & F (critical) & PC \\
\hline Current & 2 & 6.949 & 3.474 & 64.313 & 19 & 55.726 \\
\hline Gas type & 2 & 4.149 & 2.074 & 38.402 & 19 & 32.920 \\
\hline Flow rate & 2 & 0.108 & 0.054 & 1 & 19 & 3.523 \\
\hline Grove angle & 2 & 1.069 & 0.534 & 9.897 & & 19 \\
\hline Total & 8 & 12.277 & & & & 100 \\
\hline Error pooled & 2 & 0.108 & 0.054 & & & 3.523 \\
\hline
\end{tabular}

Table 7. Response table for Means of weld bead width of SS 310

\begin{tabular}{|c|c|c|c|c|}
\hline Level & Current & Gas type & Flow rate & Grove angle \\
\hline 1 & 8.503 & 8.939 & 9.465 & 9.850 \\
\hline 2 & 9.265 & 9.032 & 9.331 & 9.013 \\
\hline 3 & 10.628 & 10.424 & 9.599 & 9.533 \\
\hline Delta & 2.124 & 1.485 & 0.268 & 0.836 \\
\hline Rank & 1 & 2 & 4 & 3 \\
\hline
\end{tabular}




\subsubsection{Optimal Design of Bead Width of SS 310}

It is clear from ANOVA table for means (Table 6) that the $F$ value of current and type of gas is greater than $F$ critical. Main effect plot shows that bead width is minimum for first level current value i.e. $130 \mathrm{~A}$ and first level gas type i.e. argon. The confidence interval predict with $95 \%$ confidence so that the value of bead width for SS 310 would be $7.977 \pm 0.745 \mathrm{~mm}$.

Mean value of bead width is given by:

$$
\begin{aligned}
& \mu I_{1} G_{1}=\bar{I}_{1}+\bar{G}_{1}-\bar{Y} \\
& =8.503+8.939-9.465=7.977 \mathrm{~mm}
\end{aligned}
$$

Confidence Interval around the Estimated Mean width

$$
\mathrm{CI}_{1}=\sqrt{\frac{F_{\alpha, V_{1}, V_{2}} V_{e}}{n_{e f f}}}
$$

Where $\mathrm{F} \alpha \mathrm{V}_{1} \mathrm{~V}_{2}=\mathrm{F} 0.05: 1: 2=18.51$

$\alpha=$ Risk (0.05), Confidence $=1-\alpha$

$\mathrm{V}_{1}=\mathrm{DOF}$ for mean which is always $=1$

$\mathrm{V}_{2}=\mathrm{DOF}$ for error $=\mathrm{Ve}=2$

$\eta_{\text {eff }}=$ Number of tests under that condition using the participating factors

$\bar{Y}=$ Average bead width

$\eta_{\text {eff }}=\mathrm{N} /\left(1+\mathrm{DOFI}_{1} \mathrm{G}_{1}\right)=9 / 1+2+2=1.80$

$\mathrm{CI}=0.745$

\section{Conclusions}

1. The optimization of weld bead width in tungsten inert gas welding of austenitic stainless steel alloy was done using ANOVA. The minimum value of bead width of SS 310 is $8.27 \mathrm{~mm}$ at current value 130A.

2. The current is the most important parameter having the most significant effect on the bead width. The shielding gas type has sub-significant effect, whereas flow rate and groove angle have almost negligible effect on the same.
3. On increasing the current, the value of bead width increases which is not desirable. Among all gases, argon helps to keep bead width minimum.

4. Main effect plot shows that bead width is minimum for first level current value i.e. 130 A and first level gas type i.e. argon.

5. The confidence interval predict with $95 \%$ confidence so that the value of bead width for SS 310 would be $7.977 \pm 0.745 \mathrm{~mm}$.

\section{References}

[1] http:/en.wikipedia.org/wiki/Gas_tungsten_arc_welding

[2] Benyounis, K.Y.,.Olabi, A.G “Optimization of different welding processes using statisticaland numerical approaches - A reference guide” Advances in engineering software 39,483-496, 2008.

[3] A. Bendell, J. Disney, W.A. Pridmore, Taguchi Methods: Applicationsin World Industry, IFS Publications, UK, 1989.

[4] Kumar, V.“Application of Taguchi and FEM to Explore the Surface Properties of Glass Using USM Process” American journal of mechanical engineering, Vol. 2, No. 1, 1-7, 2014.

[5] Juang, S.C, Tarng, Y.S. "Process parameter selection for optimizing the weld pool geometryin the tungsten inert gas welding of stainless steel” Journal of Materials Processing Technology 122 (2002) 33-37.

[6] Nagesh, D.S.,.Datta, G.L, "Genetic algorithm for optimization of welding variables forheight to width ratio and application of ANN for predictionof bead geometry for TIG welding process”Applied Soft Computing 10 897-907, 2010.

[7] Dhas, E.R, Dhas, J.H. “A review on optimization of welding process” ProcediaEngineering(2012) 38544-554.

[8] Ahmet Durgutlu, "Experimental investigation of the effect of hydrogen in argon as a shielding gas on TIG welding of austenitic stainless steel” Materials and Design 25 (2004) 19-23.

[9] Durgutlu, "Experimental investigation of the effect of hydrogen in argon as a shielding gas on TIG welding of austenitic stainless steel” Materials and Design 25 (2004) 19-23.

[10] Kumar, Shahi, "Effect of heat input on the microstructure and mechanical properties of gas tungsten arc welded AISI 304 stainless steel joints.” Materials and Design 32 (2011) 3617-3623.

[11] Tseng, Hsu, "Performance of activated TIG process in austenitic stainless steel welds” Journal of Materials Processing Technology 211 (2011) 503-512.

[12] Kanga, Yarlagadda, Prasadb, Kanga, Kima, Kimc, “The effect of alternate supply of shielding gases in austenite stainless steel GTA welding” Journal of Materials Processing Technology 209 (2009) 4722-4727. 